\title{
Das regras do método, aos métodos desregrados
}

\author{
JOSÉ MACHADO PAIS
}

\begin{abstract}
RESUMO: A Sociologia que Durkheim ajudou a criar debatia-se com a necessidade de afirmar um método científico baseado num conjunto de regras que a instituíssem como um domínio de saber independente e consagrado. A Sociologia que hoje praticamos encerra uma conflitualidade crescente - não apenas em relação a outros campos de saber (conflitualidade externa) como também ao próprio nível da sua discursividade (conflitualidade interna). A hipertextualidade do social faz com que a Sociologia viva em regime multimétodo. As (pro)posições uniformes das Regras do método deram lugar a (dis)posições multiformes de métodos desregrados. Neste cenário anômico surgem vozes alarmadas com as transgressões metodológicas e anárquicas que invadem o campo da Sociologia e reclamase uma realpolitik que reunifique e ordene a discursividade sociológica. Resta saber se essa pretensão - fiel às Regras do método - é compatível com a crescente desinstitucionalização, fragmentação e individualização da vida social.
\end{abstract}

\section{Introdução}

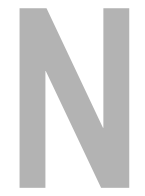

uma ocasião em que celebramos o centenário das Regras do método sociológico de Durkheim, há quem se questione - como Jean-Michel Berthelot (1995a, p. 175) - sobre se não estaremos a participar num "ritual tribal" próprio de eventos comemorativos e, em conseqüência, a empolar artificialmente a atualidade das Regras. Talvez sim, talvez não.

Talvez sim, considerando que as comemorações são normalmente utilizadas para evocações de caráter mais ou menos ritualístico. Os livros, como os cadáveres, estão expostos à corrupção do tempo, são alimento de
UNITERIMOS:

metodologia sociológica, Durkheim, As regras do método.

Esse trabalho foi apresentado no VII Congresso Brasileiro de Sociologia promovido pela Sociedade Brasileira de Sociologia, realizado na Universidade Federal do Rio de Janeiro de 4 a 6 de setembro de 1995.

Professor do Instituto de Ciências Sociais da Universidade de Lisboa 
PAIS, José Machado. Das regras do método, aos métodos desregrados. Tempo Social; Rev. Sociol. USP, S. Paulo, 8(1): 85-111, maio de 1996.

pequenos vermes e, muitas vezes, seu destinoé converterem-se em pó. Um bom pretexto, pois, para desenterrarmos as velhas Regras da estante, dando-lhes uma desempoeirada releitura. Quem sabe se, sem querer, não acabaremos deste modo por nos questionar sobre os alcances e os limites da objetividade sociológica, recuperando o seu "inconsciente" epistemológico (cf. Bourdieu, 1980).

Com efeito, uma releitura crítica das Regras do método sociológico talvez nos permita chegar à conclusão de que o que comemoramos não se esgota no ato da comemoração. De fato, o "ritual tribal" permite-nos pôr em prática o método sociológico por excelência, segundo Durkheim - o método comparativo - ao confrontarmos, a pretexto da comemoração, a Sociologia tal qual Durkheim a entendia e tal qual hoje a vivemos.

Desta confrontação parece resultar uma considerável similitude. A Sociologia que Durkheim ajudou a criar debatia-se com a necessidade de afirmar um método científico que se apoiasse num conjunto de regras que a instituíssem como um domínio de saber independente e consagrado. A autonomia da Sociologia só parecia possível na base de uma anomia disciplinar, de uma conflitualidade (externa) com outros domínios do saber. A Sociologia que hoje praticamos encerra uma conflitualidade interna de métodos (cf. Nunes, 1977), tanto mais exacerbada quanto mais desregrados são esses métodos. Não no sentido em que as regras desses métodos primem pela sua ausência mas, em contrapartida, pela sua abundância.

Em ambos os casos (ou épocas) o que está em causa é o problema da autonomia da Sociologia. Com Durkheim, a Sociologia procura fixar as suas modalidades de conhecimento no quadro de determinados enunciados que assumiam a configuração de regras. Essas regras cumpriam uma função de unificação de um novo espaço de saber, para melhor poder impor-se e distinguir-se dos demais. Em contrapartida, a Sociologia é, hoje em dia, um espaço epistêmico plural (cf. Berthelot, 1995b). Não apenas pelas múltiplas problemáticas que levanta mas também pelos múltiplos caminhos (métodos) para abordá-las. Assistimos a uma fragmentação das correntes sociológicas e a algo ainda mais paradoxal: enquanto no esforço de institucionalizar a Sociologia, Durkheim procurou afastar-se da influência de outros quadros paradigmáticos do conhecimento (em particular da Psicologia, da História, da Economia Política e da Filosofia), as múltiplas correntes da Sociologia atual parecem preferir as "transgressões metodológicas" que, como Boaventura Sousa Santos bem reconheceu, alimentam a inovação científica a partir de "contextos persuasivos que conduzem à aplicação dos métodos fora do seu hábitat natural" (Santos, 1987, p. 48). Métodos próprios da Economia, da História, da Antropologia e da Psicologia (para já não falar da Literatura ou da Psicanálise) invadem, sem pedir licença, os terrenos da Sociologia. Os métodos desregrados produzidos insinuam-se como verdadeiras profanações às Regras do método. Com algum pânico, teme-se que a Sociologia esteja perdendo o seu objeto. Como explicar as profanações das Regras do método que nos são dadas pelas transgressões metodológicas desregradas? E até 
PAIS, José Machado. Das regras do método, aos métodos desregrados. Tempo Social; Rev. Sociol. USP, S. Paulo, 8(1): 85-111, maio de 1996.

onde a Sociologia poderá ir por estes (des)caminhos?

Abalando ordens instituídas, as profanações acabam quase sempre por revestir formas de insurreição. É bem possível que a Sociologia as tenha cultivado na tentativa de ultrapassar uma certa crise de produção expressa numa excessiva "normalização" (no sentido kunhniano da expressão) do seu discurso, das suas problemáticas e das suas teorias. Mas é sabido como a períodos de profanação (insurreição) se seguem outros de sacralização (ressurreição). As comemorações são momentos de ressurreição. Ao desempoeirarmos das velhas estantes as Regras do método sociológico instauramos um ato sagrado num território profano. Não são as comemorações consagrativas?

Por que comemoramos As Regras? Não é certamente, ou apenas, porque estamos no seu centenário; se assim fosse, todos os objetos centenários seriam comemorados. Nas Formas elementares da vida religiosa - em particular, num dos capítulos que trata do culto positivo, consagrado aos "ritos representativos ou comemorativos" (Durkheim, 1982, p. 345-361), encontramos um possível fundamento. Quando Durkheim analisa os ritos de comemoração entre os Warramunga conclui que esses ritos consistem exclusivamente na rememoração do passado e na sua reatualização. Tudo transcorre em representações cujo destino é atualizar o passado mítico do clã. Ora, a mitologia de um grupo consiste, segundo Durkheim, num conjunto de crenças comuns. $\mathrm{O}$ que expressam as tradições cuja memória se perpetua é uma moral, uma cosmologia, e não tanto uma reposição histórica. Será que, ao comemorarmos as Regras, andamos à procura dessa "moral" perdida?

Wollumqua, o totem dos Warramunga, era uma serpente que por onde passava distribuía um mágico spirit-children - princípios espirituais que alimentavam a alma dos vivos (Durkheim, 1982, p. 352-353). Provavelmente, o que procuramos em Durkheim é esse poder de totem, é esse spirit-children inspirador e reunificador. Então, ao comemorarmos as Regras do método, o que nos move é uma vontade de trazermos à memória o que nos é (ou deve ser) comum. Numa época em que a Sociologia parece viver em regime de anarquismo metodológico (cf. Feyerabend, 1975), estes rituais comemorativos acabarão por assegurar uma reunificação simbólica. Ou seja, apesar de todas as nossas diferentes perspectivas teórico-metodológicas e dos nossos diferentes quadros conceptuais, sentimos necessidade de descobrir as nossas raízes comuns. Ao evocarmos Durkheim estamos produzindo, entre nós, uma solidariedade liminar que é, afinal, o tipo de solidariedade que irrompe quando o profano se cruza com o sagrado, quando a insurreição (dos métodos desregrados) clama pela ressurreição (das regras do método). De Turner (1969) sabemos, com efeito, que os rituais balanceiam entre um pólo de separação e um pólo de agregação. Entre esses dois pólos há um terreno de ambigüidades, por onde os rituais oscilam em transições inter-estruturais.

A Sociologia contemporânea vive nestes terrenos de ambigüidade, balanceando-se entre uma desregração de métodos (pólo de separação/ 
profanação) e a evocação das regras do método (pólo de reunificação/ (con)sagração). E sendo os rituais formas de transição inter-estruturais, o terreno "inter" é um terreno de liminaridade, onde se geram solidariedades que, por terem um caráter "liminar", podem revestir um aspecto subversivo. A subversão consistirá neste caso na ressurreição (insurrecional) das velhas regras de um método que se voltam a discutir, mesmo quando olhadas com alguma desconfiança ou antipatia. Independentemente das encruzilhadas a que pode nos conduzir tamanho paradoxo, saibamos aproveitar esta oportunidade de "solidariedade liminar", para nos questionarmos sobre os caminhos, os desafios e o estatuto epistemológico do conhecimento sociológico, neste centenário das Regras do Método.

\section{A "mão direita" de Durkheim}

Num velho artigo sobre "La prééminance de la main droit", Hertz (1970) mostra-nos que o sacré droit é um lugar de atração ou unificação e o sacré gauche é um lugar de repulsão e desintegração. As Regras do método inscrevem-se no pólo do sacré droit, quando Durkheim, com a sua "mão direita", dá sinais de pretender unificar (e consagrar) um campo de saber próprio - o da Sociologia. As Regras do método foram escritas para garantir um campo de coesão disciplinar, uma química social de uniões e combinações da qual emergisse um domínio de pesquisa, um acentuar de linhas de força que permitissem à Sociologia adquirir uma identidade própria. Para que a Sociologia adquirisse o estatuto de ciência era imperativo que desse estatuto ganhasse consciência.

As Regras do método não nos dão apenas - nem principalmente as regras de um qualquer método. Mais do que isso, dão-nos uma visão institucionalizada de um novo campo de saber. Creio que só tomando as Regras neste sentido é que seremos capazes de interpretar alguns enigmas da sociologia durkheimiana.

Com efeito, quais as sequiência do método proposto por Durkheim? Definição, classificação, explicação por indução metódica, seguida de enunciação de leis gerais (teorias) por comparação de resultados. No entanto, em boa verdade, Durkheim não segue à risca esta sequiência. Onde é que ela está nas Formas elementares da vida religiosa? E mesmo no Suicídio, embora parta de uma definição inicial do objeto de estudo, acaba por derivar os vários tipos de suicídio não de uma elaboração indutiva mas da sua teoria de socialização (cf. Gane, 1988).

Aliás, na conclusão das Regras do método, Durkheim é bem explícito quanto aos objetivos que persegue - a autonomização de um campo de saber - ao resumir as características do seu método sociológico: "Em primeiro lugar [afirma] é independente de qualquer filosofia (...). A sociologia não tem que tomar partido entre as grandes hipóteses que dividem os metafísicos" (Durkheim, 1989, p. 152). E em relação às relações de 
PAIS, José Machado. Das regras do método, aos métodos desregrados. Tempo Social; Rev. Sociol. USP, S. Paulo, 8(1): 85-111, maio de 1996.

promiscuidade que ameaçavam a Sociologia, Durkheim não é menos claro:

"A sociologia não é (...) o anexo de qualquer outra ciência; é ela própria uma ciência distinta e autônoma e a noção de especificidade da realidade social é de tal modo necessária ao sociólogo que só uma cultura especialmente sociológica pode preparálo para a compreensão dos fatos sociais. Pensamos que este progresso é o mais importante dos que restam à sociologia compreender" (Durkheim, 1989, p. 154).

Tomando a classificação que o próprio Durkheim faz dos ritos nas Formas elementares da vida religiosa (1982) diríamos que as Regras do método assemelham-se a ritos negativos ou ascéticos cumprindo uma função de instituição/preservação do estatuto científico da Sociologia. Aliás, muitas dessas regras são enunciadas sob a forma de interditos, com o objetivo claro de demarcação de campos (exemplos: "afastar da ciência todas as noções prévias", "a evolução social não é explicável por causas psíquicas", "a sociologia não tem de tomar partido entre as grandes hipóteses que dividem os metafísicos”...). As práticas de renúncia associadas a estes interditos (ritos negativos) são passos importantes para a afirmação da Sociologia, como domínio disciplinar autônomo.

O programa e o desafio da sociologia durkheimiana é, pois, explicitamente, o de "ruptura, fundação e conquista" (Berthelot, 1995b, p. 103). Estes intentos haviam já sido esboçados por outros discípulos de Comte, como foi o caso de Émile Littré, em artigos publicados na revista $\mathrm{La}$ philosophie positive. Em 1871, chegou mesmo a criar uma Société de Sociologie, embora de duração efêmera e sem os resultados esperados (cf. Geider, 1981, p. 345-360).

Só com a publicação das Regras se dá, verdadeiramente, uma convulsão interdisciplinar que permite à Sociologia ocupar algum espaço no meio científico e acadêmico (cf. Karady, 1976, p. 267-311). Não sem dificuldades e oposições. Durkheim vê-se obrigado a deitar mão de estratégias e alianças complexas. Primeiramente começa por ofuscar muitos dos seus potenciais concorrentes, incluindo Spencer que bastante influência tivera na sua formação (Boudon \& Bourricaud, 1984, p. 343-350). Depois entra em ruptura com domínios que eram vizinhos da Sociologia mas perigavam o seu desenvolvimento, como aconteceu com a Economia (cf. Steiner, 1994, p. 135159). Aliás, neste caso chega mesmo a minar o campo adversário, dividindoo para melhor reinar, como aconteceu quando aproximou-se dos economistas alemães para rebater as posições indesejáveis dos economistas franceses liberais (cf. Breton, 1991, p. 389-419), acabando por colaborar na Revue d'Économie Politique, criada em oposição à escola liberal ortodoxa. A mesma estratégia leva-o à escolha de outros aliados conjunturais para melhor fazer vingar os seus propósitos, como quando, sem grandes convicções e afetos, aproximou-se de juristas e moralistas (cf. Durkheim, 1975). Já a abertura de 
PAIS, José Machado. Das regras do método, aos métodos desregrados. Tempo Social; Rev. Sociol. USP, S. Paulo, 8(1): 85-111, maio de 1996.

L'Année Sociologique a alguns estudos de História parece corresponder a uma estratégia de Durkheim para alargar o domínio (vocacionalmente imperialista) da Sociologia a campos vizinhos (cf. Besnard, 1986). Finalmente, em relação às alarmadas hostes filosóficas, de onde poderiam vir os mais acérrimos ataques e os maiores perigos dissolventes, adota uma postura mais doce, convencendo-os de que só tinham a ganhar perdendo de vista a Sociologia:

"A própria filosofia tem todo o interesse na emancipação da sociologia, pois, enquanto o sociólogo não despojar suficientemente o filósofo, apenas considera as coisas sociais pelo seu lado mais geral, ou seja, o lado em que mais se assemelham às outras coisas do Universo. Ora, se a sociologia assim concebida pode servir para ilustrar com fatos curiosos uma filosofia, não pode enriquecê-la com novas perspectivas, pois nada assinala de novo no objeto que estuda” (Durkheim, 1989, p. 152).

Deste modo, não espanta que a preocupação de Durkheim, aos escrever as Regras, fosse a de definir uma espécie de Zona Sociológica Exclusiva que demarcasse razoavelmente bem as correntes do saber sociológico da interferência de outras correntes, necessariamente turvas, e impeditivas da afirmação da Sociologia (cf. Berthelot, 1995a). As maiores ameaças vinham do campo da Psicologia e da Filosofia Social. Daí as distâncias que marcou relativamente a Tarde e também a Simmel que divulgava "Sociologia" em cursos livres de Psicologia e Filosofia. Durkheim tinha por Simmel alguma estima intelectual - o primeiro número de L'Année Sociologique, editado por Durkheim, em 1986, continha um artigo de Simmel - mas não o poupou a críticas logo que se apercebeu que não o convertia. A sua Filosofia do dinheiro foi considerada uma obra cheia de "especulações ilegítimas" que acabariam por influenciar negativamente a Ética protestante e o espírito do capitalismo, de Max Weber (cf. Mommsen \& Osterhammel, 1987). Sempre que as alianças resultavam inconvenientes, Durkheim avançava a sós. Berthelot (1995a, p. 13) admira-se que Durkheim cite, nas suas obras, tão poucos autores além de citar a si mesmo. Mas os deuses não se citam, são citados. Nas Regras do método, as citações são de Comte, Spencer, Mill, Tarde, Espinas e Garofalo, e são quase sempre citações envoltas de críticas.

A “mão direita” de Durkheim aponta, então, o caminho por onde a Sociologia deveria avançar: esse caminho-que se institui em método-passa pela demarcação dos descaminhos por onde a Sociologia poderia se perder. Aliás, na história do pensamento da idade moderna vemos que o problema do método converge para o estabelecimento de múltiplos critérios de demarcação: entre a natureza e a História; o racional e o irracional; o sagrado e o profano; o normal e o patológico; entre a ciência e a metafísica; entre sapiens e demens. A própria busca de leis se converte, progressivamente, em norma de edificação de uma ordem de conhecimento (científico) que, como toda a ordem, deveria 
PAIS, José Machado. Das regras do método, aos métodos desregrados. Tempo Social; Rev. Sociol. USP, S. Paulo, 8(1): 85-111, maio de 1996.

ser convenientemente regulada, simultaneamente inclusiva e exclusiva. Um conhecimento ordenado (regulado pelas regras de um método) que melhor desse conta da ordem das coisas (isto é, dos fatos sociais), da regularidade dos fatos (que deveriam ser considerados como coisas). A sociologia durkheimiana concentra todos os seus esforços na descoberta dos fatores da ordem, na busca da coerência das representações coletivas, na acentuação das regularidades que sustentam a coesão social.

Qualquer zona exclusiva é definida por sinais exteriores de demarcação, simbólicos ou materiais: aduanas ou fronteiras, taxas ou bandeiras. A Zona Sociológica Exclusiva deveria definir-se a partir de "sinais exteriores" do social. Para Durkheim, são estes sinais exteriores que tornam a realidade social sensível, e logo possível. Em primeiro lugar, porque tal realidade é efeito de causas que lhe são "externas" e, em segundo lugar, porque essa realidade não se apresenta de forma transparente. Quais as leis que acabariam por determinar que essas causas externas produzissem a realidade dos fatos sociais? As leis da ordem - uma ordem moral, na medida em que a moral regula e ordena (Turner (ed.), 1993). Mesmo em sociedades dominadas por uma solidariedade orgânica, Durkheim conclui que, à medida que se torna mais autônomo, o indivíduo depende mais estreitamente da sociedade, e logo, de uma ordem moral, por camuflada que seja. Com efeito, na Divisão social do trabalho, uma idéia central é a de que o laço social é, antes de tudo, um laço moral. Para Durkheim, a moral entendida em sentido lato designa as regras que presidem às relações dos homens que formam uma sociedade. São regras morais que enunciam, segundo Durkheim, as condições fundamentais da solidariedade social.

Durkheim pensa numa moral única, kohlberguiana (cf. Kohlberg, 1981). Do lado do sacré droit, tudo parece sujeito a uma ordem. E, nessa medida, o Direito seria expressão dessa moral unitária, súmula de estados fortes de consciência coletiva, isto é, de crenças caracterizadas por sua permanência e precisão. A "mão direita" cria, pois, uma sociedade de direito. E a Sociologia, ao seguir este caminho, deveria partir à descoberta das leis (do direito, da moral, das convenções) que, externamente, regulam e ordenam a sociedade, nos seus aspectos mais banais - leis cujo descumprimento está sujeito a algum tipo de punição. O próprio Durkheim confessa:

"Se não me submeto às convenções da sociedade, se, ao vestir-me, não tenho em conta os usos seguidos no meu país e na minha classe, o riso que provoco e a aversão que suscito, produzem, ainda que de uma maneira mais atenuada, os mesmos efeitos, que uma pena propriamente dita" (Durkheim, 1989, p. 30).

A confissão transcrita não deixa de ser intrigante, uma vez que Durkheim advoga que as leis reguladoras (convenções sociais) devem apreender-se isoladas das suas manifestações individuais. Ou seja, Durkheim 
adota o lema escolástico individuum est ineffabile, isto é, do que é individual não se pode falar; contudo, acaba por falar dos constrangimentos sociais que sente como indivíduo. Voltaremos, mais adiante, a esta questão intrigante.

\section{Os outros "acenos de mão"}

Mas o sacré droit em que a Sociologia se instituiu - lugar de atração e unificação - sempre coexistiu com um sacré gauche, lugar de repulsão e separação. E outras mãos começam a acenar à Sociologia, mesmo no período do seu prolongado e doloroso parto. Eram ruidosas e perturbantes as polêmicas com os seguidores de Saint-Simon e Comte e, posteriormente, as que opuseram Durkheim a Tarde. Entretanto, do lado da Alemanha, Weber e Simmel faziam outros distintos e convincentes acenos à Sociologia - que Durkheim, como vimos, achou por bem ignorar.

Ou seja, uma certa ameaça de desregramento sociológico é contemporânea ao próprio nascimento da Sociologia que começa, bem cedo, a cultivar diferentes tradições sociológicas com Marx, Durkheim, Weber e Simmel, restando saber se estas diferentes tradições, com seus respectivos deuses ou pais tutelares, não traduziram, afinal, um "politeísmo" relativamente apaziguado (cf. Berthelot, 1995a, p. 184). O berço da Sociologia foi, com efeito, embalado por diferentes tradições e confrontações. Com tantas amas, este bebê exigia uma paternidade que Durkheim assume com orgulho, reconhecendo que a teia de filiações filosóficas em que a Sociologia nasceu acabaria por a fragilizar, dificultando-lhe o crescimento, retirando-lhe credibilidade.

É nesse assumir de paternidade que se levantara a "mão direita" de Durkheim, mão unificante que pretendia conferir uma unidade argumentativa e legitimadora ao discurso sociológico. Um discurso cuja principal regra é o da exigência de prova contra outros discursos que aprovam a ausência da prova porque sustentam que, em Sociologia, tudo se pode provar. Profanação suprema, de mãos que acenavam do sacré gauche.

O esforço de Durkheim que permitiu à Sociologia um amplo espaço de autonomia relativamente a outros domínios do saber não impediu que a Sociologia invadisse e profanasse outros campos de saber. Desde as suas origens, aliás, e pela mão do próprio Durkheim. Ao fugir da Psicologia - para institucionalizar a Sociologia - Durkheim envereda-se pelos terrenos da Antropologia. Não de uma Antropologia qualquer, é certo. Mas daquela que mais facilmente poderia cair na alçada da influência paradigmática da Sociologia. Sobrinho e discípulo de Durkheim, Marcel Mauss foi um continuador fiel dos ensinamentos do seu mestre, sempre alimentando a convicção de que toda a sua obra foi um desenvolvimento sistemático das idéias do fundador do L'Année Sociologique. A influência de Durkheim fazse também sentir em Lévi-Strauss, como este próprio, aliás, reconheceu (Caruso, 1969, p. 38). Quando em 1960, a Universidade de Paris comemorou 
PAIS, José Machado. Das regras do método, aos métodos desregrados. Tempo Social; Rev. Sociol. USP, S. Paulo, 8(1): 85-111, maio de 1996.

a celebração do centenário do nascimento de Durkheim (1859), Lévi-Strauss participou com o sugestivo contributo: "Ce que l'ethnologie doit à Durkheim” (Lévi-Strauss, 1973). Quando a antropologia levistraussiana insiste no fato das leis da linguagem funcionarem, ao nível do inconsciente, à margem do controle dos indivíduos falantes e, por isso mesmo, poderem ser estudadas como fenômenos objetivos (Lévi-Strauss, 1988), está fazendo um apelo durkheimiano à "exterioridade". Quando na Semiótica - e em particular com Saussure - se insiste no caráter "institucional" do sistema da língua, não se tem dúvidas em reclamar para a linguagem o estatuto de "fato social" e a sua emergência como forma de "consciência coletiva" (cf. Saussure, 1968). E o mesmo acontece quando Barthes (1981) sugere que a Semiologia da fashion se concentra não tanto no vestuário real mas nas "representações sociais" que sobre ele se moldam e recortam.

Hoje em dia, a unidade metodológica com que Durkheim pretendeu garantir a autonomia da Sociologia estilhaçou-se. Às Regras do método sucederam-se métodos desregrados, no sentido em que elas proliferam numa ordem de permissividades sem precedentes. A Sociologia faz atualmente uso dos métodos como quem faz uso de um arpão: pode ser apontado para todos os lados e com uma elasticidade notável. Dessa variabilidade desregrada surgem teorias para todos os gostos: de "rédea curta", "médio alcance" e "rédea solta".

As regras tão depressa entram em ocaso como cedem passo ao acaso (cf. Becker, 1994, p. 183-194) ou, como diria Merton, aos achados serendipity. A desregração dos métodos (porque já não há o método!) parece ser induzida pela hipertextualidade da realidade social, no sentido em que Becker a entende, isto é, uma realidade sem ordem fixa (cf. Becker, 1994, p. 193). A Sociologia lida, então, com um tecido (texto) social que vira e revira ao sabor das continências. E nesse vira social os métodos vêem-se na contingência de acertar o passo com tão melodiosas e ritmadas textualidades. Como acontece na hipertextualidade, há uma tentação (obsessão) em agarrar o social por todos os lados. As regras? Dependem dos métodos... Por sua vez, a hipertextualidade do real convida à hiper-hermeneuticidade (multimétodos). Já é corrente a simulação de métodos de análise por computador - os chamados knife métodos (cf. Meter, 1994, p. 34) - como acontece na formação de clusters com as análises fatoriais.

As duas últimas décadas foram marcadas por uma verdadeira explosão de paradigmas (cf. Henri-Cuin \& Gresle, 1992). O universo da Sociologia desdobra-se em cada vez mais subuniversos: dos quantitativistas aos marxistas; dos históricos (que também podem ser marxistas) aos interacionistas; dos etnometodólogos aos fenomenólogos; dos estruturalistas aos hermenêuticos; dos formalistas aos funcionalistas; dos sistêmicos aos semióticos (cf. Collins, 1986, p. 1336-1355). Boa parte das mais recentes e atrativas investigações sociológicas realizam-se em terrenos de fronteira: nas fronteiras do indivíduo, nas fronteiras das regiões, nas fronteiras do próprio saber. 
Os interstícios interdisciplinares são preenchidos por especialidades que se acotovelam mutuamente: sociologia histórica, antropologia política, psicologia social, etc. Discutem-se as recomposições de especialidade que resultam das fragmentações disciplinares (cf. Dogan, 1994, p. 37-53). Para alguns metodólogos não são mais as regras que orientam o método mas é este, no seu evoluir, que justifica as regras - regras que variam em função das resistências do "terreno", dos fenômenos em estudo, de critérios de gosto, etc. O desregramento dos métodos seria também determinado pelo fato das regras só surgirem quando aqueles se aplicam in vivo (cf. Morin, 1991). Mas também há quem se interrogue sobre a possibilidade de se adotar uma atitude metodológica em relação ao presente (cf. Barreyre, 1993, p. 383-392). Nesta ordem de idéias, ou de desordens, talvez Elias (cf. 1993, p. 32) tenha alguma razão quando sustenta que, afinal, os problemas de método que opõem os sociólogos entre si são perfeitamente secundários.

Os tempos da pós-modernidade acentuam as desregrações profanas. Contra a moral unitária durkheimiana e kohlberguiana, baseada em critérios de legitimidade, racionalidade, universalidade e comensurabilidade (cf. Lourenço, 1993, p. 293) - critérios presentes nas Regras do método sociológico, surgem as contra-regras profanas da pós-modernidade: o universalismo cede lugar ao contextualismo; a legitimidade dá lugar ao relativismo; a racionalidade é substituída pela narrativa; a incomensurabilidade ocupa o lugar da comensurabilidade (Lourenço, 1993, p. 293).

Todas estas contra-regras se fazem acompanhar de uma vasta gama de dúvidas metódicas. As Regras do método estipulavam que os fatos sociais constituem uma realidade autônoma que devia ser explicada em termos sociais. Mas lá surgem as dúvidas, a contra-regra. E se tomássemos os fatos ideológicos e a discursividade científica como fatos sociais? E se, por outro lado, na ânsia de emular as ciências exatas, a Sociologia acabasse por se destruir com a destruição do seu objeto de análise? E se o peso das estruturas sociais acabasse por nos retirar a capacidade de ver como elas mudam? Ese os excessos sociologizantes acabassem por nos impedir de fazer Sociologia? E se os (injustificados) complexos de inferioridade científica da Sociologia - por não conseguir ser tão exata quanto as Ciências exatas - se transformassem em razões de (falsa) supremacia? Dúvidas que se avolumam com uma dúvida ainda mais radical, embora bem mais reconfortante: e se todos estes "ses" fossem, afinal de contas, a razão de ser da Sociologia?

\section{As velhas regras resistem às novas ordens?}

Cem anos após a publicação das Regras do método sociológico, a questão que se coloca é a seguinte: será que as velhas regras do Método resistem às novas ordens sociais? A questão é tanto mais pertinente quanto é certo que, como o próprio Durkheim reconhecia, "em questões de método ... nada se pode fazer que não seja provisório" (Durkheim: 1989, p. 12). Até na medida 
PAIS, José Machado. Das regras do método, aos métodos desregrados. Tempo Social; Rev. Sociol. USP, S. Paulo, 8(1): 85-111, maio de 1996.

em que, mesmo olhando os fatos sociais como "coisas", o que acabamos por ter não são fatos, mas artefatos que refratam os fatos em maneiras de vê-los.

Ora, a modernização minou os tradicionais fundamentos dos laços sociais, dos valores, das crenças, da moral, dos imaginários coletivos, das regras do jogo institucional. Vejamos o que se passa no domínio das representações sociais. Elas existem na medida em que se inscrevem num ciclo de reprodutibilidade. Falar de reprodução pressupõe a idéia de permanência, de patrimônio, de conhecimentos, competências, instituições, valores, símbolos. Mas as representações tendem a diluir-se quando fluem em processos de socialização pluralistas e diferencialistas, como acontece na sociedade contemporânea.

Ainda que, como Philippe Ariés costuma dizer, "o pesado navio dos costumes nunca gira com muita brusquidão", assistimos a uma crescente desinstitucionalização da vida social, isto é, a uma relativa perda de capacidade das instituições para modelar os comportamentos cotidianos. As mais recentes surveys realizadas na Europa mostram bem como os inquiridos valorizam as cercanias do cotidiano: a saúde, o dinheiro, a qualidade de vida, a família, os amigos, dando, em contrapartida, pouca importância ao político, ao religioso, às ideologias, às grandes ordens institucionais. É esta desinstitucionalização que nos leva a falar das bricolages no domínio do religioso, nas famílias "recompostas", no "tráfego de votos" do espectro político, etc. Questão a debater é a de saber se as instituições tradicionais de socialização, não obstante se aparentarem debilitadas, impedirão a existência de outras e novas formas de socialidade. Tome-se, por exemplo, a irrupção do afetivo. Em sociedades tradicionais e rurais, o sentimento amoroso encontrava-se subordinado a controles familiares e comunitários (cf. Singly, 1991); logo que este controlo se enfraqueceu o "amor individualizado" parece tornar-se um "imperativo social".

Não quer isto dizer que o "individualismo moderno" passe a ser apenas interpretável como um produto de emancipação ou libertação de constrangimentos sociais. As orientações subjetivas dos indivíduos estão também organizadas socialmente, de forma não aleatória. O que parece acontecer é que ao recrudescimento do movimento de individualização das sociedades modernas, corresponderá um paralelo movimento de despessoalização. A noção de indivíduo remete à de unidade (a sociedade contida no indivíduo), ao passo que a noção de pessoa tem um sentido holístico (é o indivíduo que aparece contido e imerso na sociedade).

Nas sociedades tribais, por exemplo, a transformação da criança em pessoa implicava uma série de etapas ritualmente marcadas, envolvendo quase sempre a ação física: perfuração das orelhas, dos lábios, do septo nasal, etc. (cf. Seeger, 1975). É como se a totalidade penetrasse o elemento individualizado para, ao mesmo tempo, o incorporar na coletividade, transformando-o em pessoa. Assim acontecia nos ritos de iniciação, em 
PAIS, José Machado. Das regras do método, aos métodos desregrados. Tempo Social; Rev. Sociol. USP, S. Paulo, 8(1): 85-111, maio de 1996.

particular na fase liminar dos iniciados (cf. Turner, 1967). Protagonistas ativos (enquanto objetos e sujeitos) de processos de socialização específicos de uma fase de vida, os jovens ritualizavam, nesses processos de socialização, experiências de personificação.

De uma sociedade personificada a uma sociedade individualizada, a Sociologia não poderia deixar de reagir a esta mudança. A sociologia durkheimiana repousa numa definição personificada do indivíduo, ou seja, o indivíduo é sempre um agente socializado e as "leis sociais" repousam numa "moralidade" que tende a adequar/subordinar o indivíduo ao corpo doutrinal da sociedade. As Regras do Método são regras de uma sociologia hipersocializada. Em contrapartida, a sociologia contemporânea repousa numa concepção hipossocializada do indivíduo (cf. Ceri, 1995), como bem o demonstram algumas das novas regras e teorias do pensamento sociológico. É o que acontece com o individualismo metodológico, e algumas das suas versões mais sofisticadas, como a Rational Action Theory (cf. Coleman, 1990). Neste caso, a aceitação das normas ou valores morais depende das vantagens que dessa aceitação possa resultar, isto é, perde-se o dever de obediência às normas, sobrelevado pelos ganhos de obediência.

No individualismo metodológico dá-se uma clara redução do peso das relações verticais (imperativas) a favor das relações horizontais (estratégicas). A explicação de fenômenos coletivos e "macroscópicos" é feita a partir de comportamentos e de estratégias individuais e "microscópicas".É certo que não há nesta concepção sociológica uma defesa atomista da sociedade e, muito menos, intuitos de considerar o indivíduo como "não social"(Birnbaum \& Leca, 1986, p. 13-14). Embora o individualismo metodológico não trate de analisar as ações dos indivíduos, tomadas isoladamente, como se faz nos estudos ideográficos "puros", acaba por privilegiar um certo efeito-agregação dessas ações, ou seja, o resultado dessas ações, atitudes ou comportamentos individuais, reagrupados em "idéias tipos" (cf. Boudon, 1986, p. 45-49). Neste modelo de análise, as regras do método sociológico passam a inspirar-se em regras da Ciência Econômica. Da mesma forma que os economistas descrevem o comportamento do consumidor ou do produtor em determinadas circunstâncias, também a Sociologia passa a criar tipologias de indivíduos ("ideais-tipo"), tomando a agregação dos seus comportamentos como um efeito global a reter.

A passagem de uma perspectiva hipersocializada a uma perspectiva hipossocializada é bem clara. Este reducionismo propõe à Sociologia o ideal explicativo de outras micro-ciências - "a análise do mais complexo em termos do mais simples". Para Elster (1986, p. 61) há essencialmente duas razões pelas quais a explicação do "macro" pelo "micro" é preferível à explicação durkheimiana do "macro" pelo "macro". Por um lado, há uma razão estética: mesmo que a explicação "macro-macro" fosse robusta e fiável, haveria sempre o prazer que resulta de abrir a "caixa negra" e de descobrir o rodado do mecanismo (cf. Maffesoli, 1985, p. 114). Por outro lado, há ainda uma alegada 
PAIS, José Machado. Das regras do método, aos métodos desregrados. Tempo Social; Rev. Sociol. USP, S. Paulo, 8(1): 85-111, maio de 1996.

razão científica: passando do macro ao micro, passamos simultaneamente, da longa à curta duração, o que, por exemplo, reduz o risco de confundir explicação e correlação.

A questão metodológica em discussão é portanto a seguinte: como endogeneizar as estruturas no estudo dos comportamentos interindividuais? De que modo as ações interindividuais, em determinadas condições, renegam essas estruturas? Se, com Durkheim, a Sociologia procurava ver como a sociedade se traduzia na vida dos indivíduos, gradualmente a focagem temse orientado no sentido de ver a sociedade ao nível dos indivíduos.

Movimentos insidiosos, a favor desta nova perspectiva, começaram a fazer-se com Weber e, mais tarde, com a Escola de Chicago. Mas também em Elias se sente essa nova preocupação (Elias, 1978a e 1978b; Gleichmann, 1977; Dunning,1979; Goudsblom, 1977 e Mennell, 1980). Para Elias, o conceito de figuração diz respeito à estrutura de redes sociais mútua e dependentemente orientadas, podendo assim contribuir para rebater o posicionamento extremista de modelos sociológicos em que a realidade está "acima" ou "separada" dos indivíduos (como acontecia com Durkheim) e/ou em que estes não passam de uma "soma" abstratamente construída; por outro lado, afastando-se dos modelos que defendem a existência de uma dicotomia conceptual que opõe o indivíduo à sociedade ou que apostam numa metodológica e ontológica prioridade do indivíduo na análise social, Elias defende, em contrapartida, o conceito de interdependência entre indivíduo e sociedade. Contra a tendência de certas correntes sociológicas em representar de uma forma estática e como categorias isoladas as experiências vivenciais e as relações dinâmicas entre indivíduo e sociedade, a sociologia "figurativa" toma as relações sociais na sua forma dinâmica. Para melhor se compreender o movimento que a própria vida constitui. Necessidade que levou Norbert Elias a utilizar a metáfora da "dança" para ilustrar o seu conceito de figuração social" (1978b, p. 261-262). Ao usar este conceito, Elias pretende eliminar a antítese teoricamente postulada entre indivíduo e sociedade que Durkheim havia alimentado nas suas Regras do método. Da dança podemos falar em geral mas ninguém pode imaginar a dança-sustenta Elias - como uma estrutura isolada dos indivíduos, ou como uma mera abstração. Na realidade, contudo, o movimento da dança pressupõe uma reciprocidade de intenções, pluralisticamente orientadas, sem as quais é impossível haver dança. Como em qualquer outra "configuração social", a idéia que importa reter é a da rede de interdependências que se estabelecem, contextualmente, entre indivíduos em interação, colocando em relevo as constantes coletivas, as recorrências de grupo.

O que muitos registos sociológicos atualmente mostram é que os fenômenos culturais são uma realização coletiva mas não representam uma eleição coletiva. Estaremos perante múltiplas eleições individuais que se encontrariam sujeitas a sutis arranjos de negociação, como dizem os etnometodólogos, mediatizadas por complexos processos de engenharia de 
consentimento, como sugerem alguns sociólogos marxianos (Miliband, 1969).

Se Durkheim hoje vivesse, a sua Sociologia teria, provavelmente, de se enfrentar com o "mito do indivíduo" (Rivière \& Piette,1990, p. 10) apesar de - paradoxo supremo - esse mito tentar promover a reciclagem de uma subjetividade ameaçada pela "homogeneização do social". Será que neste paradoxo assenta, afinal, a coincidência do retorno do indivíduo com a redescoberta de Durkheim? Mas mesmo passando ao lado deste paradoxo, não the seria difícil descobrir novos sentidos sacros e religiosos na sociedade contemporânea e, com eles, novas obrigações morais generalizadas, novas normatividades e formas de "consciência comum" (cf. Prades, 1987). Os movimentos de secularização do social - colidindo, embora, com a religiosidade institucional - não fazem desaparecer a dimensão sagrada de muitas ritualidades cotidianas do mundo contemporâneo, nem toda a força coerciva, interdita e supra-individual (exteriorizada) com que Durkheim caracterizava o social.

Dir-se-ia que a sociologia contemporânea - embora não alheia aos problemas da ordem, das regularidades e das convenções - parece centrar-se preferencialmente nos problemas da desordem, das singularidades, das disjunções; ou seja, em todos aqueles problemas que se situam nas zonas intersticiais do social e que possibilitam a existência de um outro modo de fazer sociologia, mais lábil ou "romântica", como diria Gouldner (1973). Mas se esta centração na desordem relevasse, afinal, de uma preocupação latente com a ordem? Ou vendo o problema numa outra perspectiva: porque é que o "retorno do indivíduo" (cf. Touraine, 1984) coincide com a redescoberta de Durkheim?

\section{Movimentos de "contra-reforma"}

Pode dizer-se que a Sociologia vive, hoje em dia, uma balcanização dos métodos ou modos de sociologizar, em que os conflitos internos são tão ou mais relevantes que aqueles que opõem a Sociologia a outros domínios disciplinares. Proliferam etnias metodológicas que dificilmente entram em comunicação porque falam línguas diferentes (teorias e conceitos), reclamam suas próprias raças (origens) e fecham-se em seus guetos territoriais (problemáticas).

Fala-se na decomposição da Sociologia (cf. Horowitz, 1993) e os metodólogos reconhecem que só as aproximações multimétodo conseguirão rasgar os canais de comunicação entre as várias etnias sociológicas (cf. Meter, 1994, p. 25-36). Algumas das mais destacadas figuras da sociologia contemporânea, como Bourdieu, reclamam uma realpolitik científica capaz de frear as tendências anômicas que dissolvem e descaracterizam a Sociologia (cf. Bourdieu, 1995, p. 10). Tendências que resultam de uma pluralidade de modos de pensar sociológicos (ou parassociológicos) - múltiplas visões (algumas visionárias) que provocam divisões (tantas delas arbitrárias) no seio da Sociologia. Insurge-se ainda Bourdieu contra os movimentos profanos que 
PAIS, José Machado. Das regras do método, aos métodos desregrados. Tempo Social; Rev. Sociol. USP, S. Paulo, 8(1): 85-111, maio de 1996.

invadem o domínio da Sociologia, sem pedir licença: de jornalistas, políticos, estudantes insuficientemente preparados, para já não falar da mediocridade de alguns (pretensos) sociólogos que, sabe-se lá como, conseguem assentar arraiais no mundo acadêmico.

É interessante constatar que este grito de revolta contra uma certa vulgarização da Sociologia é afinal eco das mesmíssimas preocupações com que Durkheim se debatia, um século atrás. No último parágrafo das Regras do Método podemos ler:

"Não se pode esperar recrutar uma grande clientela. Mas não é esse o fim para que tendemos. Cremos, pelo contrário, que chegou o momento de a Sociologia renunciar aos sucessos mundanos, por assim dizer, e tomar o caráter esotérico que convém a qualquer ciência. Ganhará, assim, em dignidade e autoridade o que talvez perca em popularidade" (Durkheim, 1989, p. 155)

Como justificar esta busca de esoteridade? Ela parece assentar no credo de que a Sociologia, para se afirmar, tem de cultivar um habitus científico (cf. Bourdieu \& Wacquant, 1992, p. 136). Da mesma forma que o hábito faz o monge, o habitus científico faria o sociólogo, inscrevendo-o numa ordem sacra de obediência a determinados dogmas (as regras do método). O que Durkheim explicitamente não diz - mas também não desdiz e, latentemente, parece querer dizer - é que há um ethos que é próprio da ciência, com todo um conjunto de regras expressas em formas de prescrições, proscrições, preferências e permissões que se constituem em dogmas (as referidas regras) que são o "alimento espiritual" que a Sociologia deve sorver.

Estas formas elementares de religiosidade (dogmática) que se encontram presentes em qualquer campo científico adquirem um caráter esotérico baseado na consolidação de corpos doutrináveis que se afastam das crenças comuns - o que, desde logo, implica um culto prioritário de "cortes epistemológicos" em relação a tudo o que tenha a ver com o senso comum.

A legitimação das "verdades científicas" exige a otimização de performances e de procedimentos protocolares de investigação (Geertz, 1973), como acontece com os ritos religiosos que se encontram encapsulados em correspondentes performances (cf. MacAllon, 1984). Os conceitos científicos, por exemplo, têm de ser operatórios, isto é, comensuráveis. Tudo tem de ser categorizado e explicado. Tudo tem de ter uma lógica. Para onde aponta o indicador da mão daquela escultura grega? Para o caminho da eternidade? Ou o escultor é um disfarçado impostor?

Não parecem restar dúvidas quanto ao caminho para o qual a "mão direita" de Durkheim aponta. Mão direita unificadora e instituidora das vias sacras da Sociologia - as únicas capazes de a consagrarem. No fundo, o sagrado resulta da crença numa realidade superior que dá sentido à ordem do mundo. Essa "realidade superior" constitui, para Durkheim, o social-inexplicável 
para quem, fazendo parte dessa ordem, ignora os seus princípios. Por isso a insistência na incapacidade do senso comum em descodificar uma ordem que deve ser explicada cientificamente, através de um conhecimento esotérico.

O monoteísmo da sociologia durkheimiana viu-se, contudo, abalado. Alguns movimentos de contra-reforma começaram a trilhar caminhos de uma declarada agnosticidade sociológica. Outros reclamaram vias de uma sacralidade estranha e enigmaticamente esotérica, como aconteceu com o Collège de Sociologie, fundado em 1937, por Bataille, Callois e Leiris (Hollier, 1979) animadores de uma sociedade secreta (a Acéphale) que consagraria a causa pela qual lutavam - uma causa de dissidência em relação às "insuficiências científicas", às teorias de gabinete, às fraseologias mundanas, contra as quais pretendiam instituir a desrazão do anarquismo do olhar, cuja razão de ser foi devidamente acentuada num dos primeiros textos-programa do Collège: L’Apprenti sorcier (cf. Jamin, 1980).

Não deixa de ser curioso que outro dos mais controversos movimentos de contra-reforma tenha partido de um sociólogo que foi padre: Michel de Certeau. Para Certeau era necessário contrapor às formas canônicas da sociologia ortodoxa outra sociologia, mais mística talvez. Tomava-se a mística como um instrumento de reação contra a apropriação da "verdade" pelos clérigos ou letrados professionalizados (por professarem uma enfermada fé, de falsos profetas). Que privilegiava esta sociologia mística? O saber dos iletrados, a experiência das mulheres, as culturas clandestinas, em sua existência cotidiana. Na pressuposição (ou na crença, como se queira) de que o "ignorante" tem competência em matéria de "fé" (Certeau, 1985, p. 121).

Parece haver, por outro lado, um movimento de sincretização-nem sempre pacífico - na atual produção científica, isto é, um processo de síntese, de interconexão (certamente parcial) entre várias correntes teóricas (suas raízes ou manifestações). As crenças mais sólidas (marxismo, estruturalismo, funcionalismo, etc.) foram abaladas por movimentos de descendimento ou condescimento, analógicos aos movimentos que expressam a "encarnação" do cristianismo (ou de Cristo) e que os padres designam de katábasis ou sinkatábasis.

Com Durkheim, a Sociologia tentou evacuar o profano do cosmos (os individualismos, o senso comum, as relações de má vizinhança com outros domínios do saber, etc.). Cem anos depois da publicação das Regras, a Sociologia parece mais tentada a evacuar o sagrado do cosmos e a centrar-se na profaneidade da realidade comum e do conhecimento ordinário. Por outro lado, embora não seja possível separar a ordem da desordem, o certo é que a modernidade avivou a consciência da desordem, a tal ponto que o recurso às explicações pela ordem vai fazendo cada vez mais apelo à desordem. Como sustenta Balandier, as ciências sociais vivem atualmente um "estado de penitência" (Balandier, 1988, p. 63). Elas agitam-se, distanciam-se dos antigos sistemas de referência e modos explicativos, procuram novos objetos, interrogam o seu próprio saber. Já não existe nenhuma ciência social que 
PAIS, José Machado. Das regras do método, aos métodos desregrados. Tempo Social; Rev. Sociol. USP, S. Paulo, 8(1): 85-111, maio de 1996.

alimente a vocação imperialista de unificar o social, como Durkheim pretendia com a Sociologia. Outrora obcecada pela ordem e pelo equilíbrio, a Sociologia vê-se fortemente incitada a explorar o ponto de vista da desordem (cf. Balandier, 1988, p. 83), mesmo que seja para alimentar a ilusão do descobrimento de novas ordens (cf. Bauma, 1991).

Ou seja, a atenção é dada, presentemente, ao conflito, à instabilidade, à assimetria, à diversidade (cf. Touraine, 1984). A desordem, o inesperado e a turbulência fascinam; a banalidade transforma-se em mistério; a vida cotidiana é vista como uma encruzilhada mágica entre rotinas e rupturas. A própria mudança social deixou de ser teorizada a partir de proposições de validade genérica a passou a ser avaliada através do circunstancial, do possível, do conjuntural. À desordem do social parece corresponder um anarquismo do olhar sociológico. Como se o modo de ver determinasse o que é visto (ou viceversa?). Estas desordens têm provavelmente um efeito de democraticidade nas "comunidades científicas" que as leva a pulverizarem-se e a viverem em "mais controvérsia, maior diferenciação, menor integração" (cf. Jesuíno, 1993, p. 48-57). Situação que, como vimos, não impede algum alarmismo com a desregração dos métodos, levando ocasionalmente alguns de nós a pôr a mão (direita) na consciência e a refletir na conveniência de possíveis corpos doutrinários mais unificados, de onde possa emergir uma communis doctorum opinio capaz de restabelecer algum consenso num campo cada vez mais pulverizado.

\section{O lado de cá do lá}

Durkheim parte do lado de lá - do lado da "exterioridade" das "representações coletivas". Vimos que, do lado de lá (terrenos do "sagrado"...) surge uma mão unificadora (mão "direita"...) que se estende sobre as nossas cabeças, em ato de benção ou graça. Graças a essa mão - mão simbólica, invisível e unificadora - somos, pensamos e agimos desta e não de qualquer outra forma. Mão mágica, como a mão invisível de Adam Smith que tentava pôr ordem nos efeitos do liberalismo econômico do século passado.

Em contrapartida, muita da Sociologia contemporânea parte do lado de cá - o da interioridade do "aqui" e do "agora", como dizia Mead (1982). A mão reguladora do nosso cotidiano é a nossa própria mão - instrumento paradigmático do tato e instrumento chave na apreensão dos objetos, mercê da especialíssima articulação do seu dedo polegar. É em relação a este instrumento que se define a "zona manipulativa" dos indivíduos aos quais é dada, portanto, a capacidade de manipular, enquanto na perspectiva durkheimiana acabariam por ser manipulados do "exterior", do lado de lá...

Ora, o desafio que talvez se coloque, hoje em dia, à Sociologia é jogar entre cá e lá, reconhecendo que os indivíduos têm, do lado de cá, essa capacidade de manipular, muito embora estejam também sujeitos às forças do lado de lá. Quando Adão, no Paraíso, estende a mão para apanhar a maçã e 
provar o fruto proibido - paradigma manipulativo por excelência - acaba por ser tentado pelas forças de um "lá" - as forças tentadoras do mal. As forças de lá atuam cá. À Sociologia abre-se, então, um extenso campo de descobertas: a exploração do lado de cá do lá.

De que lado está Durkheim? Do lado de lá, como vimos, ou não fosse Durkheim um estruturalista avant la lettre. Mas, ao lado (longínquo) de uma sociologia "dura" das estruturas sociais, há o lado da história "branda" das representações sociais - tão branda e maleável que foi a Psicologia Social que mais dela deitou mão (cf. Jodelet, 1989). A sociedade que a sociologia durkheimiana namora é uma sociedade de "forças coletivas", eventualmente traduzíveis em séries estatísticas. O lado de cá do social quase sempre foi repudiado por Durkheim, mais preocupado com a ordem do que com o modo como ordenamos a ordem. No prefácio das Regras do método recusa-se a explicar o mais complexo pelo mais simples (Durkheim, 1989, p. 5) e, tomando o exemplo da moral, rejeita que esta seja tomada ao nível das "consciências individuais" (Durkheim, 1989, p. 49). Contudo, acaba por admitir que, "se a vida coletiva não deriva da vida individual, ambas estão inteiramente relacionadas; se a segunda não pode explicar a primeira, poderá, pelo menos, facilitar a sua explicação" (Durkheim, 1989, p. 125).

Para Durkheim, a sociedade é uma estrutura que não pode ser deduzida das interações sociais que a preenchem, quer por adição quer por abstração. Como se fosse um tema musical do qual apenas se conhecessem as variações. Na verdade, um tema musical não é um somatório de variações, da mesma forma que a sociedade não é um somatório de interações, e muito menos de indivíduos. Como mostram os psicólogos da Gestalt, reconhecemos uma melodia familiar, mesmo quando tocada num tom em que nunca a ouvimos anteriormente, isto é, fora de tom. Contudo, a melodia permanece a mesma. Compreendêmo-la como estrutura, uma seqüência de intervalos que é, na verdade, expressa através das notas, mas não nas notas. Para Durkheim, a sociedade é também expressa através dos indivíduos mas não nos indivíduos. Regra das mais sacras do método sociológico. Pois é, mas também é verdade que os indivíduos são criadores de melodias e não apenas intérpretes. À Sociologia compete também decifrar essa competência produtora de novas melodias sociais.

Com o crescente processo de divisão social de trabalho, que Durkheim tão bem estudou, e a crescente fluidez social, deixamos de andar a "assobiar" as mesmas melodias. Quer dizer, as "representações coletivas" segmentarizaram-se originando uma grande diversidade de micro-culturas e um decréscimo de importância dos fundamentos tradicionais e sagrados das ordens macro-sociais. A segmentarização das "representações coletivas" vai de par com o acentuar dos processos de individualização. Quando a estrutura social se torna menos rígida, a individualização intensifica-se. É esta alquimia da sociologia unitária durkheimiana e da sociologia plural contemporânea que importa debater. 
PAIS, José Machado. Das regras do método, aos métodos desregrados. Tempo Social; Rev. Sociol. USP, S. Paulo, 8(1): 85-111, maio de 1996.

As representações coletivas não valem menos do que valiam, mas valem de maneira diferente. De que modo elas se espelham nas representações individuais e vice-versa? É este um desafio que se coloca à sociologia contemporânea: ver o lado de lá no cá e o lado de cá no lá. As representações coletivas expressam-se através de representações individuais mas nestas encontramos também valores da subjetividade - ao modo de Nietzsche que concebia os atos humanos como atos de "preferir" ou "preterir". Ou seja, nesta concepção relativista (porque subjetivista) dos valores, a fórmula "tem valor o que é desejável" sobreleva a fórmula absolutista que sustenta que "o desejável é o valioso". As duas fórmulas enfrentam-se, aliás, em vários domínios do social, como acontece na publicidade: a publicidade coerciva produz a obrigação de consumir, enquanto a publicidade sugestiva produz o desejo de consumir.

De um lado, os valores são determinados por interesses, gostos, desejos; de outro lado, correspondem a modelos de conduta que parecem repousar em ontológicas categorias "a priori” de Kant. É o ser frente ao dever ser, o eidos frente ao ethos - contraposição que Bateson gostava de fazer quando, no estudo das mentalidades, contrapunha os aspectos cognitivos aos valorativos (cf. Bateson, 1942).

Nas Regras do método o ser aparece subordinado ao dever ser. $\mathrm{O}$ fato social generaliza-se porque é constrangedor. A sua "exterioridade" em relação às consciências individuais é claramente marcada pela anterioridade histórica das regras sociais em relação à existência individual. Isto significa que existe um processo de aprendizagem através do qual aprendemos a agir em conformidade com aquilo que se espera do nosso comportamento. A Educação, em princípio, deveria exercer essa função, como Durkheim bem o mostrou em Éducation et sociologie.

O termo facto (factum) deriva do verbo latino facere. Para Durkheim, os fatos com que mobilamos o mundo da nossa experiência foram feitos à nossa medida - um dever ser do ser - como acontece com os "fatos à medida"1 com que nos vestimos. São factos (fatos) de corte universal, de medida única. Dir-se-ia que, para Durkheim, os fatos sociais se transformam em símbolos, na medida em que os símbolos (de “syn-ballein”, lançar juntos), permitem unir o que estava separado - os fatos entre si e os indivíduos com os fatos.

No entanto, para Durkheim, a realidade social (a das representações coletivas) está acima das subjetividades. As características dessa "suprarealidade" só poderiam representar-se válida e fidedignamente se a ela se aplicasse um conjunto de regras de investigação, baseadas em princípios fundamentais: por um lado, o princípio da racionalidade que estabelece que o conhecimento deve produzir-se a partir de um conjunto de protocolos lógicos (conceituais) que permitem produzir novas idéias (inferência dedutiva) ou derivá-las a partir dos dados (inferência indutiva); por outro lado, o princípio da objetividade que toma como nível obrigatório da inquirição sociológica os referidos fatos - os quais, por serem sociais, devem
${ }^{1}$ No português falado em Portugal, usa-se facto para expressar a idéia de evento ou acontecimento, enquanto o termo fato é referido a uma peça de vestuário (terno). 
ser explicados através do social.

Resta saber se esta "objetividade" não assentará na ilusão de que as observações científicas se podem fazer sem um observador. Realismo ingênuo que supõe que a atividade de conhecer não tem nenhuma influência sobre o conhecido. Para Durkheim impunha-se investigar o mundo da realidade objetiva. Para tanto havia que chegar a esse mundo ultrapassando toda a contaminação subjetiva, a começar pela do observador. A questão que se coloca à Sociologia contemporânea mais construtivista é, precisamente, a de saber qual a objetividade do conhecimento que despreza a subjetividade da sua produção. Perspectiva construtivista que já se insinuava na teoria da relatividade de Einstein (para quem as observações são relativas ao ponto de referência do observador) e no postulado de Heisenberg que sustentava que toda a observação influi no observado.

A desconfiança em relação à realidade objetiva foi o que acabou por afastar Simmel de Durkheim. Para Simmel não há fatos objetivos, nem a Sociologia se pode definir a partir deles, uma vez que não há ciência cujo conteúdo surja de simples fatos objetivos. A interpretação e ordenação destes é sempre feita de acordo com categorias, normas ou formas. Para Simmel, cai assim por terra toda e qualquer fundamentação positivista da Sociologia baseada em fatos, ao mesmo tempo que se afasta das concepções durkheimianas que tomam como ponto de partida o conceito global de sociedade. As autênticas realidades seriam formadas por constelações de indivíduos, e perante esta realidade formal, o conceito durkheimiano de sociedade evaporar-se-ia. A única existência tangível seria a dos indivíduos - suas circunstâncias, atividades e saberes - pelo que o objeto da Sociologia seria compreendê-los, uma vez que a essência da sociedade surgiria simplesmente de uma síntese ideal que nunca poderia captar-se.

São conhecidas as críticas à sociologia durkheimiana por se inspirar num racionalismo clássico e holístico que examina, compara, esquadrilha, mede, categoriza, objetualiza... mas não exprime. Fascinada pela "exterioridade" dos fatos sociais apenas olha às realidades externas. Mas olhar não significa apenas dirigir a mirada para um real completamente "fora de nós" (do lado de lá). Olhar é também sinônimo de cuidar, zelar, guardar ações que aproximam o "outro" da nossa zona de influência. Não por acaso o termo olhar se recupera do italiano guardare e do francês regarder. Do lado de cá, o das interações sociais, podemos também sentir o peso do lado de láo dos constrangimentos sociais. Ou seja, ver a sociedade ao nível dos indivíduos pode ser uma boa estratégia (método) para perceber como a sociedade se traduz na vida deles. Afinal de contas, o social escorre, como um fluido, por toda a sociedade. E, mesmo sem abandonar a regra que sustenta que o social "está em cada parte porque está no todo, e não no todo por estar nas partes" (Durkheim, 1989, p. 35), é um desafio sociologicamente interessante ver como nas partes esse "todo ausente" - ausente porque "exterior" - se manifesta. 


\section{Conclusão}

O reconhecimento da atualidade das Regras do método sociológico, consideradas como uma das referências canônicas da Sociologia, não significa que tenhamos que aderir a todas as suas propostas, nem significa uma espécie de promoção neo-durkheimiana na Sociologia atual (cf. Berthelot, 1995a, p. 185). Aliás, o olhar histórico que qualquer ciência dirige para o seu passado cumpre outras funções que não as de validação, uma vez que a ciência não cessa de ser invalidada pela sua própria progressão (cf. Smelser, 1994, p. 12). O que importa é questionar os modos de sociologizar de outrora e os de agora, testemunhando o muito que a Sociologia atual ficou a dever a Durkheim, mesmo quando dela se afasta.

Tão criticado, o positivismo durkheimiano é um positivismo de realidades ocultas mas que, nem por isso, deixa de ser menos real. Mais: a realidade sociológica por excelência nos é dada, por Durkheim, através de entidades "intangíveis", "afactuais", como é o caso da solidariedade social, da consciência coletiva, das representações... Por exemplo, os diferentes tipos de solidariedade que estuda não são fenômenos observáveis em si mas através dos efeitos que produzem. Daí que a sociologia durkheimiana se apóie numa "causalidade generativa" (cf. Benton, 1978, p. 81-111) que acaba por influenciar a sociologia funcionalista.

É essa realidade oculta que estimula Durkheim à procura do desconhecido, dos enigmas do desconhecido, como claramente o explicita no prefácio à $2^{\mathrm{a}}$ edição das Regras do método sociológico, quando insiste em que o sociólogo "deve, ao penetrar no mundo social, ter consciência de que penetra no desconhecido; deve sentir-se em presença de fatos cujas leis são tão desconhecidas como eram as da vida antes da Biologia se ter constituído; deve estar preparado para descobrir coisas que o surpreenderão e desconcertarão" (Durkheim, 1989, p. 15).

Para Durkheim, o objectivo principal da Sociologia é o da resolução de puzzles. Se bem me lembro, somente Boudon (1994, p. 114-115) assinalou este traço distintivo e essencial da Sociologia durkheimiana. Com efeito, é o caráter enigmático dos fenômenos que Durkheim toma como critério para construir um "objeto de investigação" (Boudon, 1994, p. 114-115). Exemplos de perplexidades enigmáticas não faltam, com efeito, na obra de Durkheim: por que é que as taxas de suicídio se elevam em conjunturas econômicas favoráveis? Por que é que baixam em períodos de crise política? Por que é que acreditamos em idéias falsas não obstante os desmentidos do real, como no caso das crenças mágicas?

Os enigmas não surgem num contexto de consensos. Seria um contrasenso! Daí a aversão de Durkheim ao sensocomum com pretensões "científicas". Não ao senso comum sob a forma de rumor social ou de representação coletiva. A essas manifestações do senso comum Durkheim trata como fatos sociais: são "maneiras de pensar" reconhecíveis - como dizia 
PAIS, José Machado. Das regras do método, aos métodos desregrados. Tempo Social; Rev. Sociol. USP, S. Paulo, 8(1): 85-111, maio de 1996.

- pela particularidade de serem suscetíveis de exercer uma influência coerciva sobre as consciências particulares (Durkheim, 1989, p. 21); são "maneiras de agir, de pensar e de sentir que apresentam a notável propriedade de existir fora das consciências individuais" (Durkheim, 1989, p. 21).

Será que, ao arrepio dos critérios propostos por Durkheim, para a construção dos objetos científicos, a Sociologia se tem afastado dos terrenos inseguros do desconhecido para se refugiar nas explicações confortáveis do que já foi explicado, reforçando, deste modo, "consensos científicos" que se reproduzem sem grande refutabilidade nos registos paradigmáticos em que são produzidos? Os movimentos de contra-reforma, de que falamos, não acabarão por se reificar em novos consensos, sem terem conseguido abalar os velhos? E o politeísmo sociológico contemporâneo representará o quê, afinal, senão a multiplicidade de pequenas mas fervorosas crenças (mãos direitas em território profano)? Serão estes consensos científicos uma versão camuflada e sutil de doutas e novas formas de senso comum? Se assim for, mesmo quando se enraízam ou refugiam num politeísmo sociológico doutrinal, tais consensos podem constituir-se num "obstáculo epistemológico". Tremendo paradoxo com que a Sociologia contemporânea se teria, então, de enfrentar!

Nem os fatos impediriam as crenças falsas alimentadas pela Sociologia pois, como Durkheim nos preveniu, os sociólogos têm boas razões para não se deixarem impressionar pelos fatos, mesmo quando estes enfraquecem suas teorias, quanto mais quando as confirmam. Os fatos, eles mesmos, podem acabar por confirmar as crenças falsas, se levarmos a sério as conclusões de Durkheim nas Formas elementares da vida religiosa (1982): os rituais destinados a fazer chover ou a facilitar a reprodução dos rebanhos ocorrem numa época em que os cultivos têm necessidade de chuva e, portanto, onde é provável que chova e, também, numa época em que os animais se acasalam.

Mas se é real o paradoxo de uma certa consensualização da discursividade sociológica ao nível das várias "seitas", escolas ou correntes do politeísmo sociológico contemporâneo, saibamos então despertar a sociologia dessa sonolência dispersa - "dogmática" porque consensual (cf. Boudon, 1994, p. 106); saibamos colocar como imperativa a necessidade de ruptura com essa consensualidade fragmentada, com a mesma energia com que Durkheim estabelecia a necessidade de rupturas com as pré-noções, abrindo assim caminho para o construtivismo sociológico; saibamos, finalmente, ultrapassar uma certa concepção cartesiana das regras do método: ter um método não significa apenas ter um instrumento de prova ou demonstração; nem uma gazua para arrombar portas escancaradas; os métodos estão também orientados para as descobertas, para os enigmas do desconhecido, para a resolução dos paradoxos. No prefácio à primeira edição das Regras, Durkheim aponta-nos o caminho: "se procurar o paradoxo é próprio de um sofista, evitálo, quando imposto pelos fatos, é próprio de um espírito sem coragem ou sem fé na ciência" (Durkheim, 1989, p. 2). Na pegada desta regra talvez consigamos 
PAIS, José Machado. Das regras do método, aos métodos desregrados. Tempo Social; Rev. Sociol. USP, S. Paulo, 8(1): 85-111, maio de 1996.

afirmar o estatuto científico da Sociologia contra algum "cientificismo" sonolento que aparece sempre que a ciência carece de espírito de descobrimento e criação (cf. Nisbet, 1979, p. 12).

Recebido para publicação em novembro/1995

PAIS, José Machado. From the rules of method to the disregular methods. Tempo Social; Rev. Sociol. USP, S. Paulo, 8(1): 85-111, May 1996.

ABSTRACT: The Sociology Durkheim helped to create dealed with the necessity of affirming a scientific method based on a combination of rules concentrated in institutionalizing an independent dominion of knowledge. The Sociology we practise nowadays shows a growing conflict - not only with other fields of knowledge (external conflict) but also on the level of its own discursivity (internal conflict). The hipertextuality of the social leads Sociology to a regime of multimethod. Uniform (pro)positions of the Rules of sociological method give place to the multiform (dis)positions of disregular methods. In this anomical context appear voices alarmed because of the methodological and anarchical transgressions inviding the field of Sociology, and a realpolitik which reunifies and ordenates sociological discursivity is claimed for. The question is to know whether this pretension - loyal to the Rules of sociological method - is compatible with the growing disinstitutionalization, fragmentation and individualization of social life.

\section{REFERÊNCIASBIBLIOGRÁFCAS}

BALANDIER, Georges. (1988) Le désordre, éloge du mouvement. Paris, Fayard.

Barreyre, Jean-Yves. (1993) Marches et démarche dans la ville. Société, $n^{\circ} 42$.

BARTHES, Roland. (1981) O sistema da moda. Lisboa, Edições 70.

Bateson, G. (1942) Naven. Stanford, Stanford University Press.

Bauman, Z. (1991) Modernity and ambivalance. Cambridge, Polity Press.

BECKER, Howard S. (1994) Foi por acaso: conceptualizing coincidence. The Sociological Quarterly, vol. 35, nº 2 .

Benton, Ted (1978) Philosophical foundations of the three sociologies. London, Routledge \& Kegan Paul.

UNITERMS:

The rules of sociological method, sociological methodology, Durkheim. 
Berthelot, Jean-Michel. (1995a) 1895 Durkheim. L'avènement de la sociologie scientifique. Toulouse, Presses Universitaires du Maril. . (1995b) Les vertus de l'incertitude. Paris, PUF.

BESNARD, P. (1986) L'impérialisme sociologique face à l'histoire. In: Historiens et sociologues aujourd'hui. Paris, CNRS.

Birnbaum, Pierre \& Leca, Jean (dir.). (1986) Sur l'individualisme. Presses de la Fondation Nationale des Sciences Politiques, Paris.

Boudon, R. \& Bourricaud, F. (1984) Herbert Spencer ou l'oublié. Revue française de sociologie, XXV, 3.

Boudon, Raymond. (1986) Individualisme et holisme dans les sciences sociales. In: Birnbaum, P. \& LeCA, J. (dir.). Sur l'individualisme. Paris, Presses de la Fondation Nationale des Sciences Politiques.

- (1994) Durkheim et Weber: convergences de méthode. In: HirschHorn, Monique \& Coenen-Huther, Jacques. Durkheim, Weber: vers la fin des malentendus? Paris, L'Harmattan.

Bourdieu, Pierre. (1980) Pour une sociologie des sociologues. In: Questions de Sociologie. Paris, Éd. de Minuit.

. \& WACQUANT, Loïc J. D. (1992) Réponses pour une anthropologie réflexive. Paris, Seuil.

(1995) La cause de la science. Comment l'histoire sociale des sciences sociales peut servir le progrès de ces sciences. Actes de la recherche en sciences sociales, 106-107. Mars.

BRETON, Y. (1991) Les économistes français et les questions de méthode. In: BRETON, Y. \& LutFalla, M. (eds.). L'Économie politique en France au XIX siècle. Paris, Economica.

Caruso, P. (1969) Conversaciones con Lévi-Strauss, Foucault, Lacan. Barcelona, Anagrama.

Ceri, Paulo. (1995) La conception hipo-socialisée de l'action. In: Dubet, François \& Wieviorka, Michel (dir.). Colloque de Cerisy. Penser le sujet. Autour d'Alain Touraine. Paris, Fayard.

Certeau, Michel de. (1985) Le nouvel observateur, 25/09.

Coleman, James S. (1990) Foundations of social theory. Cambridge (Massachusetts) e London, The Belknap Press of Harvard University Press.

Collins, R. (1986) Is 1980s sociology in the doldrums? American Journal of Sociology, vol. 91, nº 6 .

Dogan, Mattei. (1994) Morcellement des sciences sociales et recomposition des spécialités autour de la sociologie. Revue Internationale de Sciences Sociales, 139. 
Dunning, E. \& Sheard, K. (1979) Barbarians, gentlemen and players. Oxford, Martin Robertson.

DurKhEIM, Émile. (1975) Textes 1: eléments d'une théorie sociale. Editados por V. Karady. Paris, Minuit.

. (1982) Las formas elementales de la vida religiosa. Madrid, Akal/ Universitária (1 ${ }^{\text {a } e d i c ̧ a ̃ o: ~ 1912) . ~}$

. (1989) As regras do método sociológico. Lisboa, Editorial Presença (1 ${ }^{a}$ edição: 1895).

Elias, Norbert. (1978a) What is sociology? Londres, Hutchinson.

. (1978b) The civilising process. Oxford, Blackwell.

. (1993) Engagement et distanciation. Contributions à la sociologie de la connaissance. Paris, Fayard.

Elster, Jon. (1986) Marxisme et individualisme méthodologique. In: Birnbaum, P. \& LecA, Jean (dir.). Sur l'individualisme. Paris, Presses de la Fondation Nationale des Sciences Politiques.

FEYERABEND. (1975) Against method: outline of an anarchistic theory of knowledge. London, New Left Books.

GANE, M. (1988) On Durkheim's rules of sociological method. London, Routledge.

GeERTz, Clifford. (1973) The interpretation of cultures. New York, Basic Books.

GeIDER, R. L. (1981) René Worms, l' organicism et l' organization de la sociologie. Revue française de sociologie, XXII, 3.

Gleichmann, P. \& Goudsblom, J. \& Korte, H. (1977) Human figurations: essays for Norbert Elias. Amsterdam, Amsterdams Sociologisch Tijdschrift.

Gouldner, Alvin. (1973) For sociology: renewal and critique in sociology today. London, Allen Lane.

GoudsBlom, J. (1977) Sociology in the balance. Oxford, Basil Blackwell.

Henri-CuIn, Charles \& GResle, François. (1992) Histoire de la sociologie. 2 tomos. Paris, La Découverte.

Hertz, R. (1970) La prééminance de la mais droit. In: religieuse et folklore. $1^{\text {a }}$ edição 1909. Paris, PUF. . Sociologie

Hollier, D. (1979) Le collège de sociologie. Paris, Gallimard.

Horowitz, Irving Louis. (1993) The decomposition of sociology. Oxford, Oxford University Press.

JAMIN, Jean. (1980) Un sacré col lège ou les apprentis sorciers de la sociologie. Cahiers Internationaux de Sociologie, vol. LXVIII.

Jesuíno, Jorge Correia. (1993) Comunidade científica: dinâmica e fronteira. 
In: Estruturas sociais e desenvolvimento. Actas do II Congresso Português de Sociologia, Lisboa, volume II. Editorial Fragmentos.

JoDELET, Denise. (1989) Les représentations sociales. Paris, PUF.

KARADY, V. (1976) Durkheim, les sciences sociales et l'Université: bilan d'un semi-échec. Revue française de sociologie, XVII, 2.

KoHLBerg, L. (1981) Essays on moral development. New York, Harper \& Row.

LÉVI-Strauss. (1973) Anthropologie structurele deux. Paris, Plon. . (1988) De près et de loin. Paris, Odile Jacob.

LOURENÇo, Orlando M. (1993) Em defesa da moral kohlberguiana: só entra quem souber geometria. Revista portuguesa de pedagogia, ano XXVII, $n^{\circ} 2$.

MacAllon, Jonh. (1984) Rite, drama, festival, spectacle: rehearsals toward a theory of cultural performance. Philadelphia, Institute for the Study of Human Issues.

MAfFesoli, Michel. (1985) Nouvelles expériences sociales et formalisation. In: Bourdin, Alain \& HirshHORn, Monique (dir.). Figures de la ville. Autour de Max Weber. Paris, Éditions Aubier.

Mead, G. H. (1982) Espíritu, persona y sociedad. Barcelona, Paidós.

Mennell, S. (1980) Sociological theory: uses and unities. Londres, Nelson.

Meter, Karl M. (1994) Méthodologie sociologique. Revue Internacionale des Sciences Sociales, 139.

MiLiband, R. (1969) The state in capitalist society. London, Weidenfeld \& Nicolson.

Mommsen, W. J. \& Osterhammel (eds.). (1987) Max Weber and his contemporaries. Unwin Hyman.

Morin, E. (1991) Arguments autour d'une méthode. Paris, Seuil.

NunEs, A. Sedas. (1977) Questões preliminares sobre as ciências sociais. Lisboa, Editorial Presença, Gabinete de Investigações Sociais.

Prades, J. (1987) Persistance et métamorphose du sacré. Paris, PUF.

Rivière, Claude \& PietTe, Albert (dir.). (1990) Nouvelles idoles, noveaux cultes. Paris, Éditions L'Harmattan.

SANTOS, Boaventura Sousa. (1987) Um discurso sobre as ciências sociais. Porto, Edições Afrontamento.

Saussure, F. (1968) Curso de linguística general. Buenos Aires, Losada.

SEEger, Anthony. (1975) The meaning of body ornaments: a Suyá example. Ethnology, vol. XIV, nº 3 . 
PAIS, José Machado. Das regras do método, aos métodos desregrados. Tempo Social; Rev. Sociol. USP, S. Paulo, 8(1): 85-111, maio de 1996.

Singly, F. de (ed.). (1991) La famille, l'état des savoirs. Paris, La Découverte.

SMELSER, Neil J. (1994) Les théories sociologiques. Revue Internationale de Sciences Sociales, 139.

Steiner, Philippe. (1994) Durkheim, les économistes et la critique de l'économie politique. Économie et Sociétés, nº 19, 4.

TourAINE, Alain. (1984) Le retour de l'acteur. Essai de sociologie. Paris, Fayard.

TuRnER, Stephen (ed.). (1993) Émile Durkheim: sociologist and moralist. London, Routledge.

TURNER, Victor. (1967) The forest of symbols: aspects of ndembu ritual. New York, Cornell University Press.

. (1969) The ritual process: structure and anti-structure. Chicago, Aldine. 
PAIS, José Machado. Das regras do método, aos métodos desregrados. Tempo Social; Rev. Sociol. USP, S. Paulo, 8(1): 85-111, maio de 1996. 